\title{
Crisis intervention: the professionals' perspective
}

\section{A questionnaire survey}

\section{AIMS AND METHOD}

To describe the attitudes of the professionals of a multi-disciplinary crisis intervention service (CIS) towards the service they provide. To establish whether there are differences in attitudes between the different professional disciplines involved. A questionnaire was mailed to all the professionals working in the Barnet CIS $(n=94)$. Differences were analysed using the Kruskal-Wallis test.

\section{RESULTS}

The overall response rate was $84 \%$. Statistically significant differences were found between the different disciplines in 10 of the 37 questions (27\%) on the questionnaire. Opinions differed most on issues of safety and acceptance of clinical responsibility.

\section{CLINICAL IMPLICATIONS}

Despite general agreement on most issues, we found differences of opinion in important areas such as arrangements for team safety and clinical responsibility. These differences may create tensions within the multi-disciplinary groups and may influence the attitudes of professionals to crisis work. Measures need to be taken to address these issues in order to improve morale and staff satisfaction.
The Barnet crisis intervention service (CIS) is the longest established CIS in the UK and has been operative since 1970. Barnet is a North London borough with a population of about 300000 . Although initially introduced to support the families of patients discharged from hospital (especially from the long-stay wards) and to help those patients adjust to life in the community (Ratna, 1978), the service now provides assessment and short-term management of patients presenting as psychiatric emergencies.

The crisis team is composed of a trainee psychiatrist with at least 6 months of postgraduate experience in psychiatry, a community psychiatric nurse (CPN) and a psychiatric social worker (PSW). The rationale for inclusion of these specialities is to attempt to identify and meet the psychiatric, social and psychological needs of the patients. They provide a 24-hour service, 7 days a week. The team is always supervised by a consultant on-call. There are two CIS teams operating at any time, one for each side (East and West) of the borough. Referrals are accepted from medical practitioners of any speciality and from other agencies via the patient's general practitioner. During working hours, the referrals are taken by a 'crisis coordinator' who, after screening the calls, arranges for the team to visit. Out of hours the junior doctor coordinates the calls. The team has a quality standard such that patients should be assessed within 4 hours of the referral. The team follows a multi-disciplinary approach to assessments, which take place not only in the accident and emergency departments of local hospitals, but also in the community and in police stations. After the assessment the team formulates a care plan, which is discussed with the patient and significant others. Unless admission is indicated, those patients requiring acute psychiatric care are followed up for a maximum of 6 weeks, after which the patient's care is handed over to the appropriate community mental health team. There are weekly multi-disciplinary meetings where issues relating to the functioning of the CIS are discussed and clinical cases reviewed (Barnet Healthcare NHS Trust, 1999. Crisis Intervention Guidelines. Available from the author upon request).

Initially, the CIS followed the crisis intervention philosophy set up by Lindeman and Caplan (Aguilera \& Messik, 1982). However, there seems to be no consensus as to what constitutes crisis intervention among practitioners (Hobbs, 1984), and it has been shown that practitioners working in the CIS may have different attitudes towards the same intervention approach (Winter et al, 1987).

Different models of crisis intervention are required for different types of crisis. The Barnet CIS deals with what Baldwin (1978) described as "psychiatric emergencies". With the closure of large psychiatric hospitals there have been decreasing numbers of acute beds available, and a growing trend towards treatment in the community. Crisis intervention has been reported to reduce the number of admissions to a psychiatric unit (see Szmukler, 1987, for review)

Referrals to the Barnet CIS have shown a steady increase within recent years (see Fig. 1), creating an increasingly stressful situation for its staff. Political initiatives such as the Care Programme Approach (CPA), and growing expectations of accountability by professionals involved in acute psychiatric services, create further stresses and potential conflicts among the different disciplines within the CIS.

While increasing numbers of crisis intervention services are being established in the UK, relatively little has been reported on the particular stresses experienced by CIS staff and their views on the service they provide. It was felt timely to survey the members of the Barnet CIS in order to describe their attitudes to crisis work, and to note important differences as a way of attempting to address potential conflicts within the service. 
R

original

papers

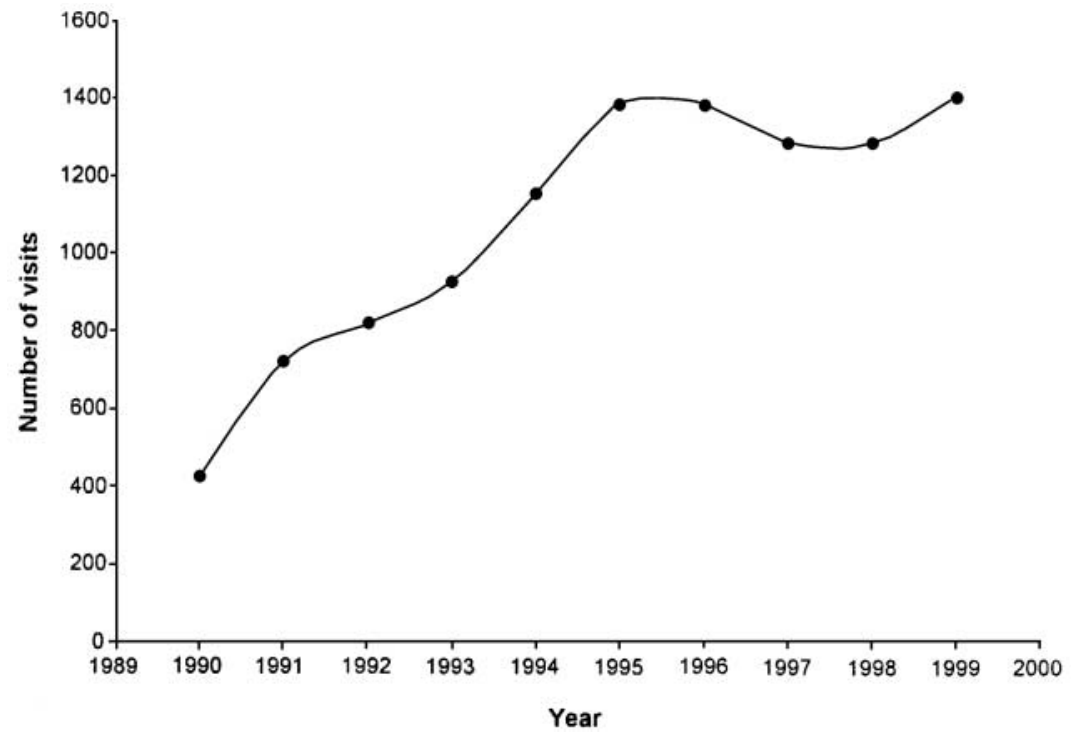

Fig. 1. Trend in number of crisis visits 1990-1999

\section{Method}

We developed a questionnaire composed of 37 questions. Each stem was accompanied by a 5-point interval rating scale (Likert type), ranging from 'completely disagree' to 'completely agree'. It reflected the referral process, as detailed above, and incorporated questions covering service volume, safety arrangements, staff satisfaction and clinical responsibility. The questionnaire was mailed to all 94 professionals of the different disciplines involved in the Barnet CIS (15 consultant psychiatrists, 13 junior doctors, 40 CPNs and 26 PSWs). Two mailings were made for each professional in order to ensure the highest response rate possible.

As the data were categorical, and hence nonnormally distributed, differences between professional groups were analysed using the Kruskal-Wallis test (a non-parametric analogue of the one-way ANOVA). We had initially used the Chi-square test, which gave very similar results, but the relatively low number of professionals in particular disciplines resulted in a considerable number of empty cells in the various $5 \times 4$ tables (5-point scale by 4 disciplines), so the test had to be discarded.

\section{Results}

The overall response rate was $84 \%$ (79/94). Response rates for each professional group were: consultant psychiatrists 93\% (14/15), junior doctors 92\% (12/13), CPNs 95\% (38/40) and PSWs 57\% (15/26).

There was general agreement in saying that patients were usually physically fit for interview and that a good standard of care is provided by a multi-disciplinary approach, but opinions were divided when considering whether visits were often delayed because a team member was engaged in other activities. Interviews were not thought to be unnecessarily prolonged as a result of three disciplines being involved. All disciplines felt that, whenever possible, patients should be assessed at home. Setting up care plans was not viewed as a source of disagreements, but the CIS was felt to be underresourced.

Difficulties in finding beds, necessitating extracontractual referral placements, were reported as a problem. Two major difficulties were identified in relation to Mental Health Act assessments; the frequent unavailability of an independent doctor approved under Section 12(2) and difficulties in arranging a police escort when needed.

All disciplines thought that working in the CIS was a valuable experience, and professionals felt well supported by senior colleagues and colleagues from other disciplines.

Ten of the 37 questions revealed statistically significant differences of opinion between disciplines. Table 1 shows the percentage of the different professionals that agreed with each statement and the accompanying $P$ value. Divergent views between professionals were reported regarding the volume of referrals (with CPNs being less likely to consider referrals to the CIS as being appropriate), safety arrangements and issues about clinical responsibility.

Fifty-eight per cent of CIS staff reported having been threatened and $21 \%$ had been assaulted (with consultants showing the greater proportion). However, despite this only $19 \%$ reported frequently feeling unsafe while on CIS duty.

There were significant differences in opinions on the issue of clinical responsibility. Where CPNs and PSWs tended to feel that clinical responsibility for patients was shared by the team, the majority of junior doctors and consultants felt that the doctor held overall clinical responsibility. Moreover, junior doctors felt that they were clinically responsible in the majority of cases when the on-call consultant was not contacted. This view was also held by $62 \%$ of the consultants. It was also noted 


\begin{tabular}{|c|c|c|c|c|c|c|}
\hline & $\begin{array}{l}\text { Consultants } \\
(n=14)\end{array}$ & $\begin{array}{l}\text { Junior doctors } \\
(n=12)\end{array}$ & CPNs $(n=38)$ & PSWs $(n=15)$ & Total $(n=79)$ & $\begin{array}{l}\text { Kruskal-Wallis } \\
P \text { values }\end{array}$ \\
\hline Referrals are appropriate & 64 & 58 & 24 & 73 & 46 & $0.002 * *$ \\
\hline $\begin{array}{l}\text { CIS not to be involved in most } \\
\text { referrals }\end{array}$ & 29 & 42 & 61 & 20 & 44 & $0.02^{*}$ \\
\hline Too many referrals & 57 & 42 & 67 & 20 & 52 & $0.004^{* *}$ \\
\hline CIS responds within 4 hours & 64 & 92 & 92 & 93 & 87 & $0.044^{*}$ \\
\hline CIS is delayed by team member & 38 & 50 & 47 & 40 & 45 & 0.717 (NS) \\
\hline Patients generally available & 43 & 100 & 87 & 87 & 81 & $0.002 * *$ \\
\hline Patients often unfit for interview & 0 & 0 & 13 & 13 & 9 & 0.324 (NS) \\
\hline MDT work = good care & 79 & 83 & 82 & 87 & 82 & 0.932 (NS) \\
\hline MDT support from all disciplines & 50 & 33 & 50 & 53 & 48 & 0.869 (NS) \\
\hline Appropriate time spent in each visit & 39 & 67 & 82 & 87 & 73 & $0.019^{\star}$ \\
\hline Questions by others are irrelevant & 31 & 25 & 16 & 7 & 18 & 0.079 (NS) \\
\hline $\begin{array}{l}\text { Long visits because full team } \\
\text { participates }\end{array}$ & 15 & 42 & 34 & 27 & 31 & 0.734 (NS) \\
\hline Patients to be seen at home & 77 & 58 & 60 & 80 & 67 & 0.488 (NS) \\
\hline Good safety arrangements & 15 & 33 & 45 & 73 & 44 & $0.021 *$ \\
\hline Frequently feel unsafe or at risk & 15 & 17 & 26 & 7 & 19 & 0.105 (NS) \\
\hline Occasionally threatened & 67 & 58 & 53 & 67 & 58 & 0.73 (NS) \\
\hline Occasionally assaulted & 33 & 17 & 16 & 27 & 21 & 0.255 (NS) \\
\hline $\begin{array}{l}\text { Disagreements arise in setting up } \\
\text { care plan }\end{array}$ & 23 & 17 & 21 & 7 & 18 & 0.154 (NS) \\
\hline Team shares clinical responsibility & 23 & 25 & 47 & 73 & 45 & $0.039 *$ \\
\hline $\begin{array}{l}\text { If consultant not aware, junior } \\
\text { doctor responsible }\end{array}$ & 62 & 83 & 29 & 13 & 40 & $<0.0005^{* *}$ \\
\hline CIS plans lack resources & 69 & 83 & 76 & 73 & 76 & 0.918 (NS) \\
\hline Good bed availability & 31 & 42 & 0 & 33 & 18 & $<0.0005^{\star *}$ \\
\hline $\begin{array}{l}\text { Extra-contractual referral is difficult } \\
\text { to arrange }\end{array}$ & 92 & 100 & 92 & 80 & 91 & 0.338 (NS) \\
\hline All disciplines available for follow-up & 7 & 0 & 3 & 13 & 5 & 0.207 (NS) \\
\hline $\begin{array}{l}\text { After hand over CMHT provides plan } \\
\text { without delay }\end{array}$ & 23 & 8 & 16 & 14 & 16 & 0.640 (NS) \\
\hline MHA assessment readily organised & 23 & 25 & 18 & 53 & 27 & 0.132 (NS) \\
\hline Bed available after MHA assessment & 38 & 25 & 13 & 47 & 26 & 0.101 (NS) \\
\hline $\begin{array}{l}\text { No transport problems after MHA } \\
\text { assessment }\end{array}$ & 23 & 42 & 40 & 33 & 36 & 0.935 (NS) \\
\hline $\begin{array}{l}\text { Easy to obtain police escort after } \\
\text { MHA assessment }\end{array}$ & 8 & 25 & 32 & 40 & 28 & 0.331 (NS) \\
\hline CIS work is a valuable experience & 92 & 100 & 92 & 100 & 95 & 0.531 (NS) \\
\hline $\mathrm{CIS}$ work is satisfying & 42 & 33 & 50 & 87 & 53 & $0.044^{*}$ \\
\hline $\begin{array}{l}\text { Good support from senior } \\
\text { colleagues }\end{array}$ & 54 & 75 & 71 & 60 & 67 & 0.759 (NS) \\
\hline Good support from other disciplines & 75 & 50 & 71 & 87 & 71 & 0.191 (NS) \\
\hline MDT meetings are valuable & 46 & 33 & 68 & 60 & 58 & 0.238 (NS) \\
\hline $\begin{array}{l}\text { MDT has meeting place to review } \\
\text { cases and make care plans }\end{array}$ & 15 & 33 & 49 & 80 & 47 & $0.003^{* *}$ \\
\hline $\begin{array}{l}\text { MDT meetings well attended by all } \\
\text { disciplines }\end{array}$ & 23 & 25 & 13 & 20 & 18 & 0.214 (NS) \\
\hline
\end{tabular}

original papers

NS=no significance; ${ }^{*} P<0.05 ;{ }^{*} P<0.01$.

CPN, community psychiatric nurse; PSW, psychiatric social worker; CIS, crisis intervention service; MDT, multi-disciplinary team; CMHT, community mental health team; MHA, Mental Health Act.

that junior doctors were the professional group that were least likely to report that working in the CIS was satisfying and fulfilling (33\%).

Finally, opinion was divided on the question of whether the multi-disciplinary meetings were thought to be of value. The majority of psychiatrists felt that the meetings were not an appropriate venue at which to review cases and discuss care plans.

\section{Discussion}

Although there are limitations to this study, such as lower response rates from the PSWs, the overall response rate suggests that the views expressed are likely to be broadly representative of the professionals involved in the CIS.

There seems to be agreement on the majority of issues affecting the CIS among the different disciplines 
involved in its functioning. However, significant differences of opinion have been detected on issues of importance, such as security arrangements and clinical original papers

responsibility. The impact of these differences on clinical practice merits further attention. A multi-disciplinary approach to practice is felt to be of paramount importance. This would entail not only an appropriate training common to all disciplines, but adequate support from senior colleagues, team building and renewal of core values, aiming, as suggested by Tyrer (1998), at a common philosophy of care.

It is not known to what extent the differences in opinions observed within the different disciplines from the $\mathrm{CIS}$ are unique, or whether these would occur in another multi-disciplinary team setting. This is outside the scope of this paper, but could be the subject of a further study.

It is plausible that the attitudes and views of the CIS professionals may have a bearing on the ability of the service to operate effectively. Similar surveys, perhaps conducted on a regular basis, might serve as a means of allowing the views of professionals to be explored and shared. This may in turn have a beneficial affect on the $\mathrm{CIS}$, helping to ensure its efficient and cohesive operation.

We have not attempted to correlate the attitudes of $\mathrm{CIS}$ professionals with patient outcome measures such as patient satisfaction. Keeble et al (1997) showed high levels of satisfaction of patients and significant others with the service provided by the CIS.

The issues raised here are of importance to existing crisis services and to those that may be planning to establish a CIS

\section{Acknowledgements}

We would like to thank Jane Simpson for her help in the initial stages of the project, and Drs Butler, Ikkos, Margerison and Ratna and Professor Winter for their helpful comments on the manuscript. We would also like to thank Jill Terry and her colleagues at the Edgware Community Hospital library for their kind help.

\section{References}

AGUILERA, D. \& MESSIK, J. (1982) Crisis RATNA, L. (1978) The Practice of Intervention. Theory and Methodology Psychiatric Crisis Intervention. St (4th edn). Missouri, USA: Mosby. $\quad$ Albans, Hertfordshire: Napsbury BALDWIN B. A. (1978) A paradigm for Hospital League of Friends. the classification of emotional crises: implications for crisis intervention. SZMUKLER, G. I. (1987) The place of crisis intervention in psychiatry. Australian and New Zealand Journal of Psychiatry, 21, 24-34.

\section{$48,538-551$.}

HOBBS, M. (1984) Crisis intervention in theory and practice: a selective review. British Journal of Medical Psychology, 57, 23-34.

TYRER, P. (1998) Cost-effective or profligate community psychiatry? British Journal of Psychiatry, 172, 1-3.

KEEBLE, P., METCALFE, C., RILEY,T., et al (1997) Cross purposes. Health Services Journal, 107, 28-29.

WINTER, D. A., SHIVAKUMAR, H., BROWN, R. J., et al (1987) Explorations of a crisis intervention service. British Journal of Psychiatry, $151,232-239$

Fernando Lazaro Specialist Registrar, Addenbrooke's Hospital, Cambridge, Elena Kulinskaya Senior Statistician, University of Hertfordshire, ${ }^{*}$ Robert Tobiansky Consultant Old Age Psychiatrist and Honorary Senior Lecturer, Department of Old Age Psychiatry, Colindale Hospital, Colindale Avenue, London NW9 5HG; tel: 02089522381

Psychiatric Bulletin (2001), 25,98-101

SEAN WHYTE AND ANDREW BLEWETT

\section{Deliberate self-harm}

\section{The impact of a specialist DSH team on assessment quality}

\section{AIMS AND METHOD}

A repetition after 5 years of a prospective case note audit, looking at the impact of a recently established deliberate self-harm (DSH) assessment team on the quality of DSH assessments at Kettering general hospital.
RESULTS

A specialist DSH team achieved improvement in the quality of psychiatric assessments for the majority of patients who harmed themselves. Assessments of mental state by accident and emergency ( $A \& E$ ) and medical staff before referral to the psychiatric team remain problematic.

\section{CLINICAL IMPLICATIONS}

Setting up a specialist team to assess patients who harm themselves can improve the quality of the psychiatric care they receive, but emphasis must still be placed on an adequate assess ment of mental state by medical and nursing staff in $A$ \& $E$ and on medical wards.
Presentations to accident and emergency (A \& E) departments after deliberate self-harm (DSH) are common (over 150000 annually in the UK) and becoming more so (House et al, 1998). These patients suffer high rates of psychiatric disorder (Morgan et al, 1975) and are 100 times more likely than the average member of the population to commit suicide in the year after presentation (Greer \& Bagley, 1971). Although patient assess- ments do not reliably predict the risk of future DSH (Hawton \& Fagg, 1995), they can identify patients with treatable mental disorder (House et al, 1998). The Department of Health recommends that every patient have a 'specialist psychosocial assessment' before discharge from hospital (Department of Health and Social Security, 1984). Assessments by A \& E staff alone have been shown to omit important items such as continuing 